\title{
International Metallographic Contest 2014
}

\author{
Revised Rules-Fewer Classes and Larger Prize Money! \\ Deadline for entries is July 19, 2014.
}

(C) Springer Science+Business Media New York and ASM International 2013

The International Metallographic Contest is an annual event co-sponsored since 1972 by the International Metallographic Society and ASM International. Its goal is to advance the science of microstructural analysis by providing an opportunity for those interested in material properties and characterization to display their work and communicate significant scientific information.

There are five different classes of competition covering all fields of optical and electron microscopy. In
Classes 1 through 3 multiple images and captions are expected to be used to describe how metallography was used to help solve a problem or to describe a unique or unusual technique. Classes 4 and 5 are for artistic pictures. It is a truly international competition showcasing the finest work of metallographers, scientists, technicians, and students from around the world. The contest is open to all (except contest judges), including nonmembers.
FIB-Damaged Surface of AlAgCu Ternary Eutectic: This image of a FIB milled directionally solidified $\mathrm{AlAgCu}$ eutectic was awarded Second Place in Class 9 of the 2013 International Metallographic Contest. It was submitted by Amber Genau, University of Alabama at Birmingham,

Birmingham, Ala

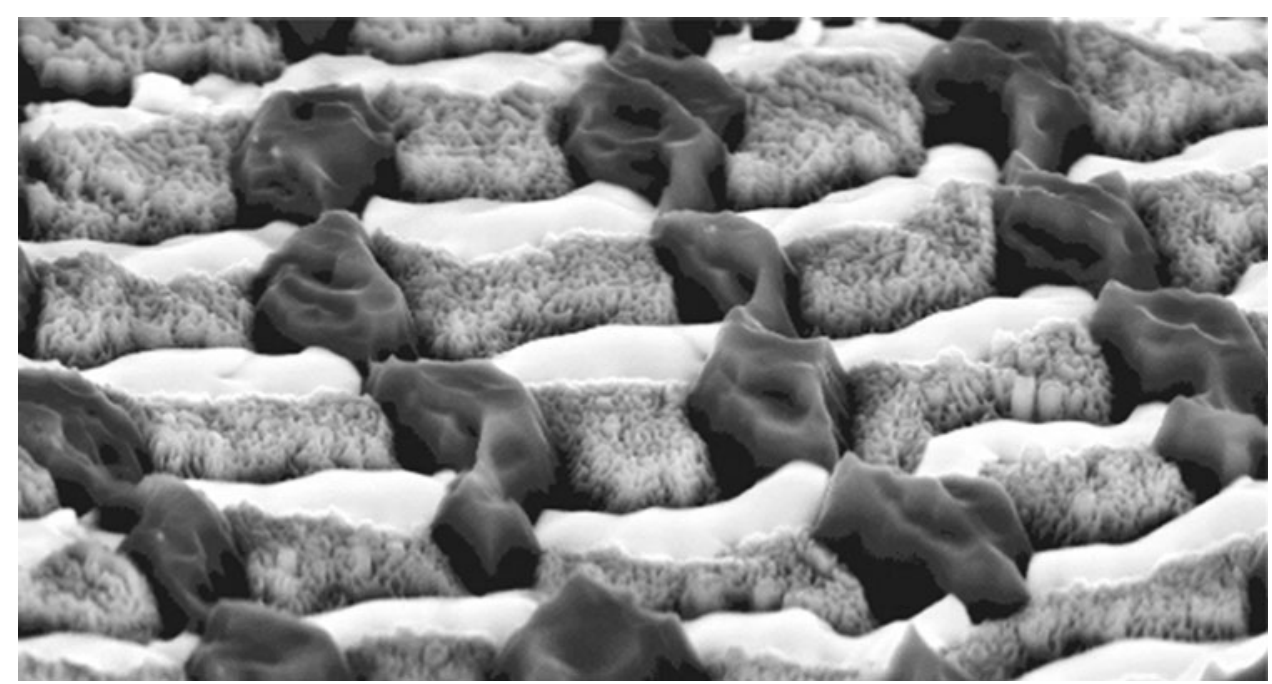


Psychedelic Nuclear Fuel Rods: This image was awarded Third Place in Class 10 of the 2013 International Metallographic Contest. It depicts uranium dicarbide oxidized after chemical etching. The image was submitted by Barbara Deschamps, CEA Marcoule, Bagnols-sur-Cèze, France

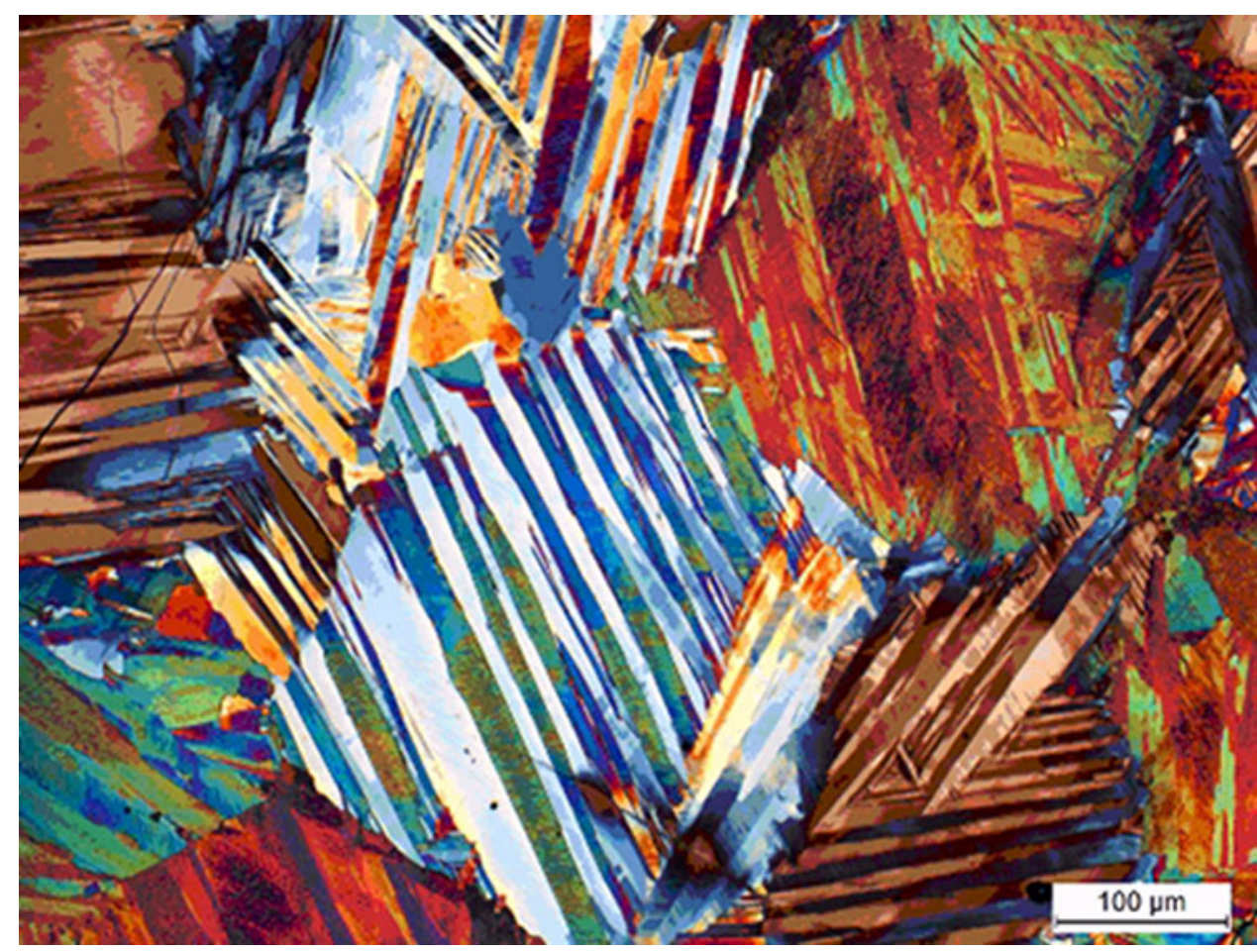

The Best-in-Show receives the most prestigious award available in the field of metallography, the Jacquet-Lucas Award, which includes a cash prize of $\$ 3,000$. The award is named in honor of Dr. Francis F. Lucas, a research microscopist at Bell Labs, who pioneered the use of high magnification and ultraviolet microscopy, and Dr. Pierre Jacquet, who developed the technique of electrolytic polishing, which led to thin-foil electron microscopy. The award has been endowed by Buehler since 1976.

First place winners in Classes 1, 2, 4, and 5 receive $\$ 500$ and first place winners in Class 3 (student entries) receive $\$ 1,000$ and the George L. Kehl Award plaque. The DuBose-Crouse Award is presented for innovation in metallography in Classes 1, 2, and 3. Second and third place winners in all Classes receive $\$ 200$ and $\$ 100$, respectively.
All entries are displayed immediately after judging at the IMS Technical meeting and again in the fall during the annual ASM meeting. Selected winning entries are also displayed at the ASM/IMS headquarters at Materials Park and are available for short term exhibition at universities, libraries, etc.

Send entries to:

Jeff Stewart

24 Butterworth Drive

Attleboro, MA 02703

USA

For additional information including complete rules, tips for creating a winning entry, judging guidelines, and examples of winning entries, visit www.metallography.net or contact Contest Chair Alice Kilgo at ackilgo@sandia.gov. 